\title{
Porous Silk Scaffold Derived from Formic Acid: Characterization and Biocompatibility
}

\author{
Ting Zhang, ${ }^{1,2}$ Qianwei Xiong, ${ }^{2}$ Yuxi Shan $\mathbb{D D}^{1}{ }^{1}$ Feng Zhang $\mathbb{D}^{3},{ }^{3}$ and Shijun Lu ${ }^{4}{ }^{4}$ \\ ${ }^{1}$ Department of Urology, The Second Affiliated Hospital of Soochow University, Suzhou, Jiangsu, China \\ ${ }^{2}$ Department of Urology, Children's Hospital of Soochow University, Suzhou, Jiangsu, China \\ ${ }^{3}$ College of Textile and Clothing Engineering, National Engineering Laboratory for Modern Silk, Soochow University, \\ Jiangsu, Suzhou 215123, China \\ ${ }^{4}$ The Affiliated Stomatological Hospital of Soochow University, Suzhou Stomatological Hospital, Suzhou 215005, China
}

Correspondence should be addressed to Yuxi Shan; drsanyx@sina.com and Shijun Lu; lu.sj@foxmail.com

Received 8 June 2021; Revised 4 July 2021; Accepted 8 July 2021; Published 16 July 2021

Academic Editor: Luca Valentini

Copyright (c) 2021 Ting Zhang et al. This is an open access article distributed under the Creative Commons Attribution License, which permits unrestricted use, distribution, and reproduction in any medium, provided the original work is properly cited.

Silk porous scaffold possesses 3D space structure for cell adhesion and tissue growth and demonstrates promising applications in biomedical engineering. In this study, a porous silk scaffold was prepared from formic acid, and its morphology, structure, mechanical properties, and biocompatibility were characterized. The preparation process involved silk dissolution in formic acid and salt leaching in water, avoiding widely used organic solvent-induced crystallization including methanol or ethanol. The resulting porous silk scaffolds showed good pore structure, stable silk II crystalline structure, good mechanical properties, and enhanced cell biocompatibility. Therefore, these findings demonstrate that porous silk scaffold derived from formic acid has great potential applications as 3D scaffold for cell culture and tissue repair.

\section{Introduction}

Silk is a unique material, which has historically been regarded as high-grade raw materials of textile for its strength and luster. Recently, silk has become a promising biomaterial for tissue engineering because of several desirable properties [1]. In particular, these properties include biocompatibility, biodegradation, excellent mechanical properties, and versatility in processing into multiple materials formats [2]. Porous silk scaffold, one of the regenerated silk materials, has attracted considerable attention because it can provide a versatile $3 \mathrm{D}$ porous structure which is known to play a critical role for cell attachment, proliferation, migration, and tissue growth, as well as for nutrient and waste transport [3].

Porous silk scaffolds can be fabricated by a variety of methods, including gas foaming, lyophilization, and salt leaching [4]. Although lyophilization is a useful method to prepare porous silk scaffolds, the resulting scaffolds usually show separate layers or lamellar structures which will cause the loss of compressive properties and affect its application as a biomaterial [5]. To date, silk dissolved in hexafluoro-2-isopropanol (HFIP) has been widely applied to prepare porous scaffolds using the salt-leaching method [6]. However, the toxicity, high volatility, cost, and further post-treatment with organic solvents such as methanol and ethanol render the necessity for alternative solvents [7].

Formic acid (FA) is an excellent solvent for dissolving regenerated silk, and the silk-FA solution is stable at least 2 days, indicating the slight molecular cleavage caused by FA [8]. Silk nanofibers [9] with uniform diameter and silk films [10] with high homogeneity, smoothness, and optical transparency have been prepared from silk-FA solution. More importantly, besides the ability of FA in dissolving silk, FA can induce the formation of $\beta$-sheet structure effectively during its evaporation [11]. Here, FA was used as a sustainable solvent for dissolving silk and then preparing porous silk scaffolds with the salt-leaching method. The process required no post-treatment with methanol or ethanol, and 
the resulting scaffolds show good pore structure and biocompatibility.

\section{Material and Methods}

2.1. Preparation of B. mori Silk-FA Solution. Silk aqueous solution was prepared as described previously [12]. The aqueous silk solution was lyophilized to prepare regenerated silk fibroin. Silk-FA solution was prepared by dissolving the above lyophilized silk fibroin in formic acid (FA), yielding a $20 \%(\mathrm{w} / \mathrm{v})$ silk-FA solution.

2.2. Preparation of Porous Silk Scaffold. A schematic diagram of porous silk scaffold process is shown in Figure 1. Silk scaffolds were prepared by adding $3.4 \mathrm{~g}$ sodium chloride particles $(300 \sim 400 \mu \mathrm{m})$ into $1 \mathrm{ml}$ silk-FA solution. FA was allowed to evaporate overnight resulting in solidified silk/ $\mathrm{NaCl}$ composite. Afterwards, the silk/ $\mathrm{NaCl}$ composite was immersed in excess water for about 3 days to completely remove $\mathrm{NaCl}$. As a control, the silk/ $\mathrm{NaCl}$ composite was firstly immersed in ethanol or methanol for $1 \mathrm{~h}$ to induce $\beta$-sheet structure and then rinsed with excess water to achieve hydrated silk scaffolds. Finally, the hydrated silk scaffolds were placed at $-20^{\circ} \mathrm{C}$ for $24 \mathrm{~h}$ to freeze and then lyophilized for $72 \mathrm{~h}$ to generate porous silk scaffolds.

2.3. Characterization. The morphology of silk scaffolds was observed with the S-4800 scanning electron microscope (SEM, Hitachi, Tokyo, Japan) at $3 \mathrm{kV}$. Pore size of porous silk scaffolds was analyzed with ImageJ.

The structure of the scaffolds was analyzed by using the X-ray diffractometer (XRD, X'PERT PRO MPD, PANalytical Company, the Netherlands) with $\mathrm{CuK}$ radiation at $40 \mathrm{kV}$ and $30 \mathrm{~mA}$.

The porosity of the porous silk scaffolds was determined by liquid displacement with hexane as the displacement liquid as the previous report [13].

The compressive properties of the scaffolds in wet conditions were measured as our previous report [5]. The Instron 3365 testing frame (Instron, Norwood, MA) with a $500 \mathrm{~N}$ loading cell was used. The compressive modulus was calculated as the slope of the stress-strain curve between 3\% and $8 \%$ [14]. Five samples were carried out for each group.

As our previous report [5], the bone marrow mesenchymal stem cells (BMSCs) were isolated and seeded in the porous silk scaffolds. The cell morphology (stained with FITC-phalloidin (Sigma-Aldrich, St. Louis, MO)) on the scaffolds after 4 days culture was examined by confocal microscopy. BMSCs proliferation was determined using CCK-8 assay conducted as the previous report [15]. Statistical analysis was performed by one-way analysis of variance (ANOVA). Difference was considered significant when $p \leq 0.05$.

\section{Results and Discussion}

Based on the dissolution of regenerated silk fibroin in FA, the $3 \mathrm{D}$ porous silk scaffolds were fabricated by salt leaching
(Figure 1). FA had been widely used to prepare silk filaments [16], nanofibers [9], and film [17]. The conformation of silk dissolved in FA was mainly random [18] and kept stable with time [8], suggesting that FA was an excellent solvent for silk [17]. On the other hand, the silk fibroin molecules were easy to aggregate and transform to $\beta$-sheet structure as FA evaporation, suggesting the opposite role of FA in promoting silk crystallization. The first role made FA a good solvent for preparing silk solution, and the second role endowed FA with the ability to fabricate silk scaffolds with water stability directly.

The cross-sectional morphology of the resulting silk scaffolds is shown in Figure 2. The silk scaffolds showed welldefined 3D structures, and a more uniform and good pore structure was present in the water-rinsed scaffolds. The irregular pore structure in the methanol- or ethanol-treated scaffolds was likely due to the effect of organic solvents on silk molecules [7]. The pore size and porosity of silk scaffolds were about $350 \mu \mathrm{m}$ and $90 \%$, respectively (Figures 3(a) and $3(\mathrm{~b}))$. The pores were interconnected by a number of smaller pores, which were same as the previous report [7]. Circular pore structure with diameter range from $10 \mu \mathrm{m}$ to $50 \mu \mathrm{m}$ was observed on the surface of the pore wall (Figure 2). The porous structure can provide space for targeted cell and tissue growth, so the water stability of silk scaffold is very important [19]. To achieve water stability, the regenerated silk material must undergo post-treatment, such as organic solvent treatment, and water annealing [13]. In this study, the preparation process of silk porous scaffold does not need post-treatments because formic acid played multiple functions in the preparation of silk porous scaffold, serving as solvent dissolving silk and inducing structural transition to $\beta$-sheet structure [8]. The formation of $\beta$-sheet structure was determined by FTIR and XRD analysis, which endowed the silk scaffold with water stability.

FTIR spectra of silk scaffolds rinsed with methanol, ethanol, and water are observed, as shown in Figure 4(a). All silk scaffolds showed adsorption peaks at 1627 and $1525 \mathrm{~cm}^{-1}$, indicating $\beta$-sheet structure. X-ray diffraction spectra of silk scaffolds were conducted to confirm the results of FTIR spectra. The diffraction peaks indicated a mainly $\beta$-sheet structure for all scaffolds (Figure $4(\mathrm{~b})$ ), in agreement with the FTIR results. The silk scaffolds rinsed with methanol, ethanol, and water all demonstrated a $\beta$-sheet structure. Methanol and ethanol were known to induce formation of $\beta$-sheet [13], but water exposure only promoted silk I structure [20]. Presumably, the evaporation of FA responded for $\beta$-sheet structure in water-rinsed silk scaffolds. Therefore, silk scaffolds with stable silk II structure and good pore structure could be directly prepared using FA as dissolving solvent and water as rinsing solvent.

The matrix stiffness has significant impact on cellular behavior and tissue [21]. Figure 5 shows the mechanical properties of silk scaffolds. The silk scaffolds rinsed with methanol, ethanol, and water had the compressive modulus of $137 \mathrm{kPa}, 153 \mathrm{kPa}$, and $185 \mathrm{kPa}$, respectively. The waterrinsed scaffold had a higher compressive modulus than the methanol and ethanol rinsed scaffolds. In the previous study, the compressive modulus of silk scaffolds increased with the 


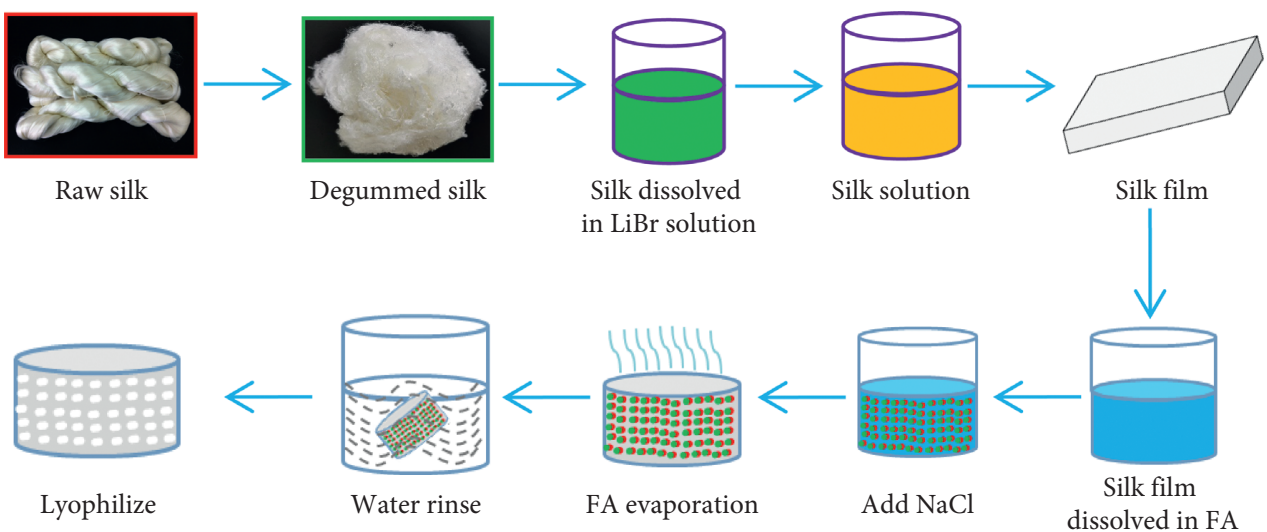

FIGURE 1: The scheme of the basic process to prepare porous silk scaffolds.
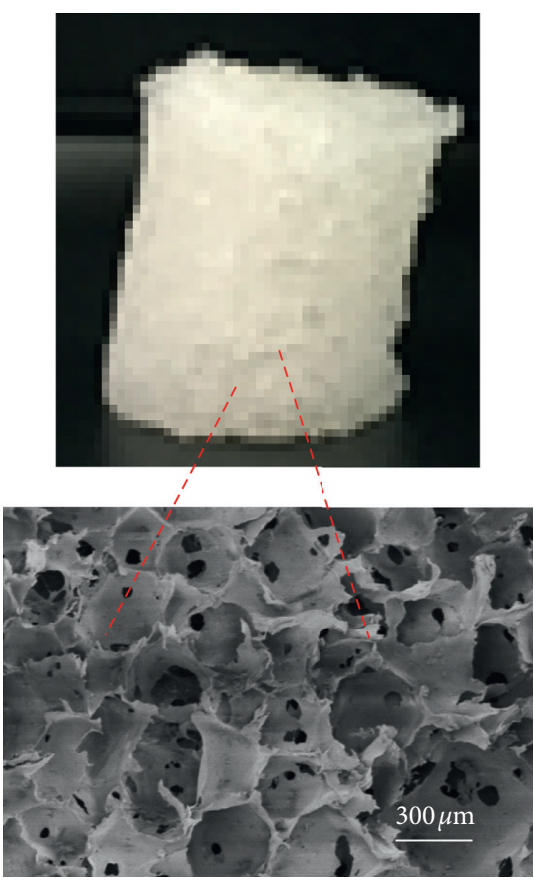

(a)
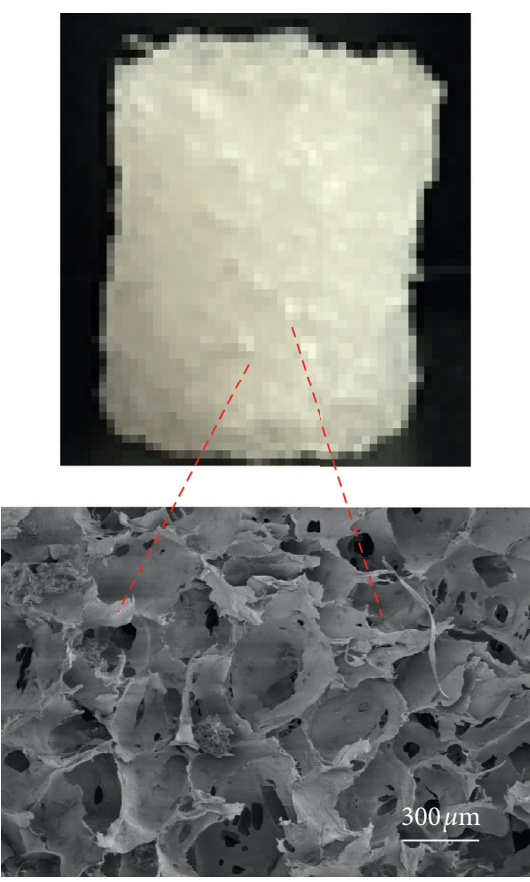

(b)
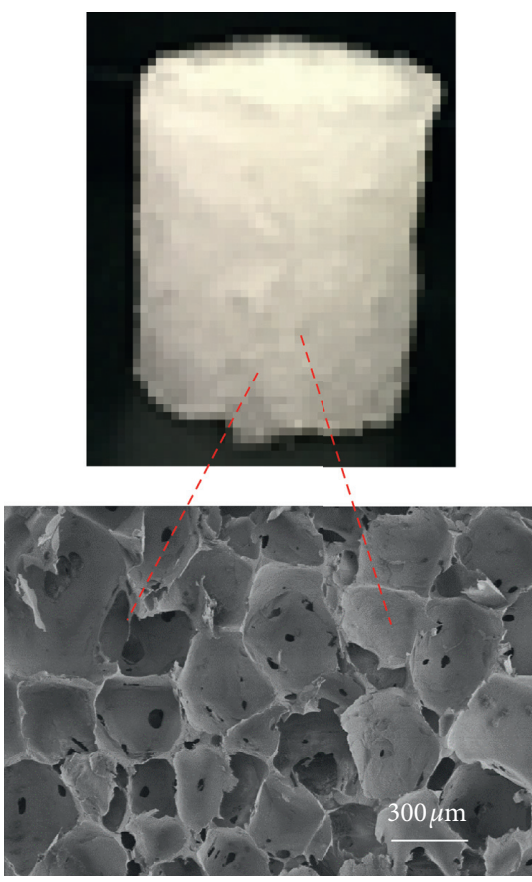

(c)

FIgURE 2: SEM images of the cross section of porous scaffolds rinsed with methanol (a), ethanol (b), and water (c).

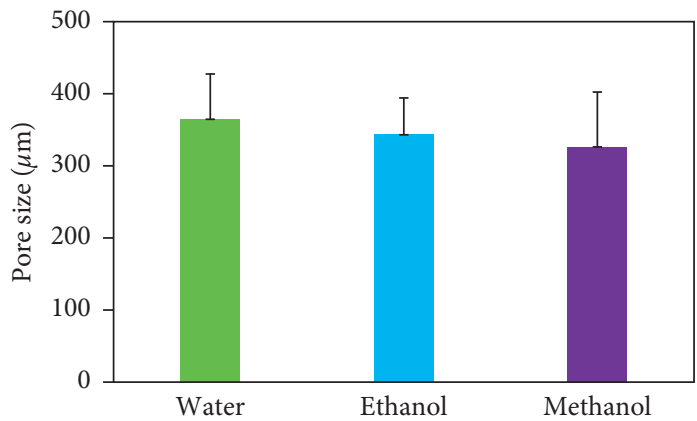

(a)

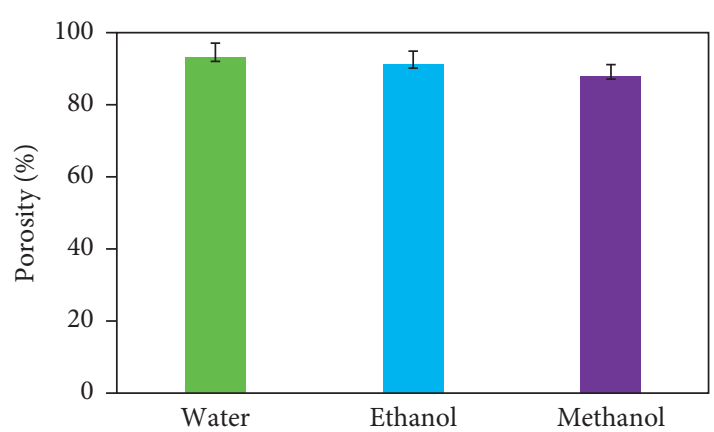

(b)

Figure 3: Pore size (a) and porosity (b) of silk scaffolds post-treated with methanol, ethanol, and water. 


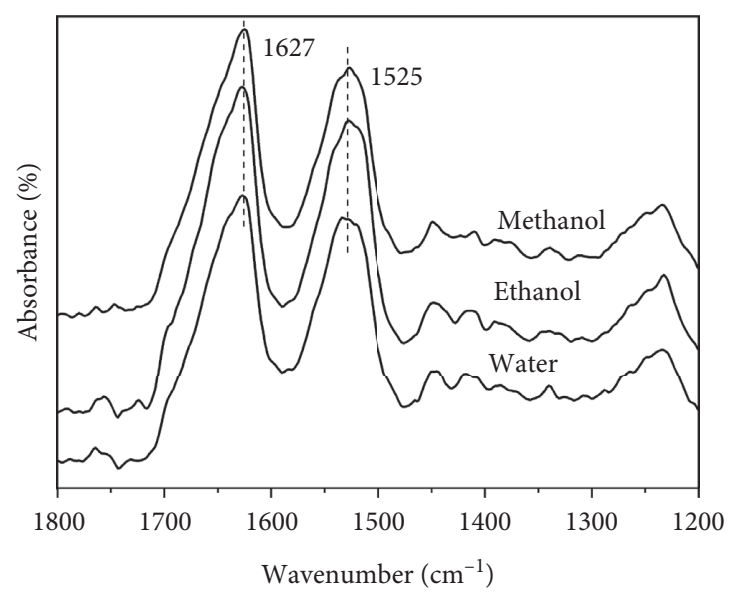

(a)

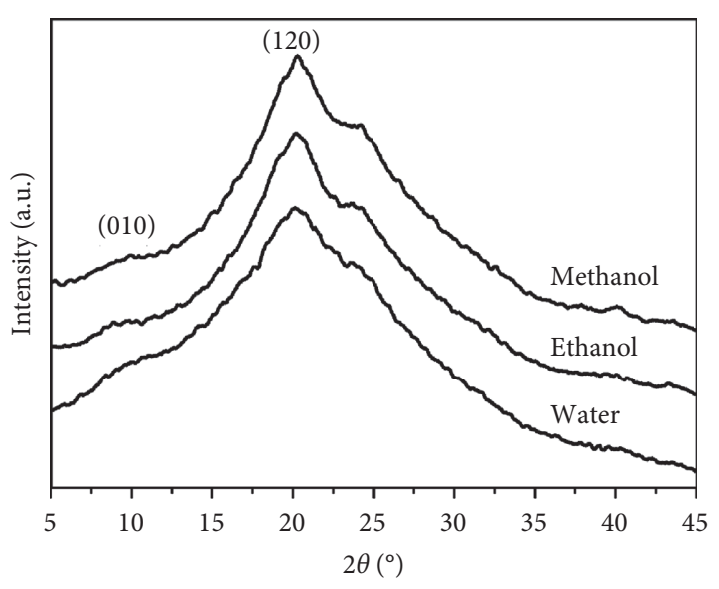

(b)

FIGURE 4: FTIR spectra (a) and XRD spectra (b) of silk scaffolds post-treated with methanol, ethanol, and water.

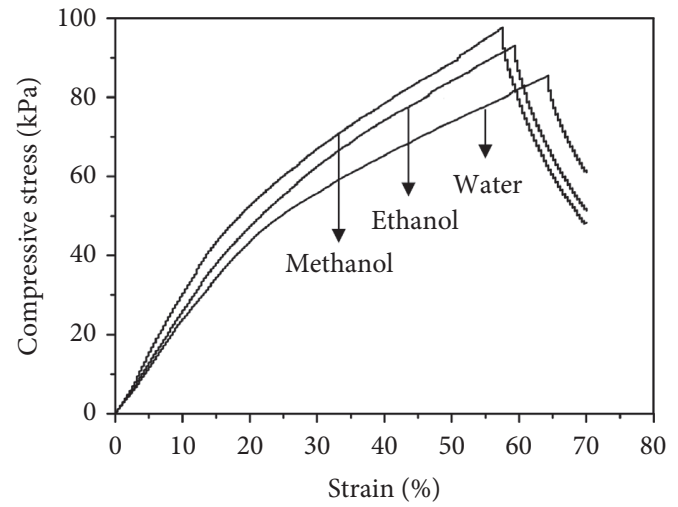

(a)

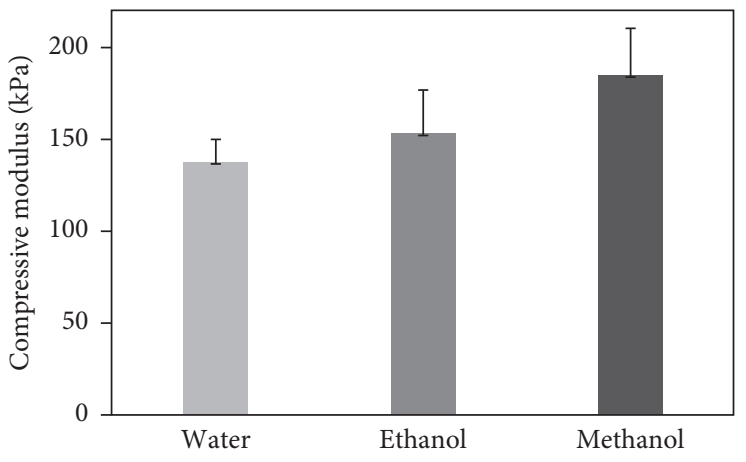

(b)

Figure 5: The stress-strain curves (a) and compressive modulus (b) of silk scaffolds post-treated with methanol, ethanol, and water.

decrease in pore size [7]. The decreased pore size created more pore wall sites which can distribute the applied stress and resist deformation. In addition, the water treatment was mild, and the resulting scaffold showed more uniform pore structure (Figure 2), which was reported to improve the mechanical property of polymer scaffolds [22]. The mechanical property of scaffolds was an important tool to regulate stem cell fate and targeted tissue regeneration [23].

To evaluate the properties related to cell compatibility, primary BMSCs were cultured in the porous silk scaffolds rinsed with water, methanol, and ethanol. Figure 6(a) shows the confocal microcopy images of BMSCs on silk scaffolds. By day 4, fewer cells were observed on the methanol-treated silk scaffolds, and the cell spreading was poor. When ethanol-treated silk scaffold was used for cell culture, more cells with improved cell spreading were observed. The waterrinsed silk scaffolds demonstrated significantly better cell growth and spreading than methanol- and ethanol-treated silk scaffolds, suggesting that the surface of water-rinsed silk scaffold favored cell attachment and spreading. The proliferation of BMSCs on the different treated scaffolds for 2-6 days was evaluated by CCK-8 assay (Figure 6(b)). The survival and continued proliferation of BMSCs was found on the surface of all silk scaffolds. The difference of cell proliferation activity between each day was significant $\left({ }^{*} p<0.05\right)$ for the water-rinsed scaffold and organic solvents (methanol and ethanol) treated scaffold.

Silk fibers have been traditionally utilized as sutures in surgery for centuries. Recently, regenerated silk materials have been explored for possible applications in biomedicine [1]. A lot of studies indicated the cell attachment and proliferation on silk fibroin materials [2]. The silk materials support cell attachment and long-term proliferation. In addition, the organic solvent used to prepare silk materials also significantly influences the cell compatibility due to the residual solvent [24]. In this study, the used methanol and ethanol could be the reason that causes slow cell proliferation behavior compared with water rinse process. Similar result has been reported that silk film treated with water vapor showed higher cell proliferation than silk film treated 

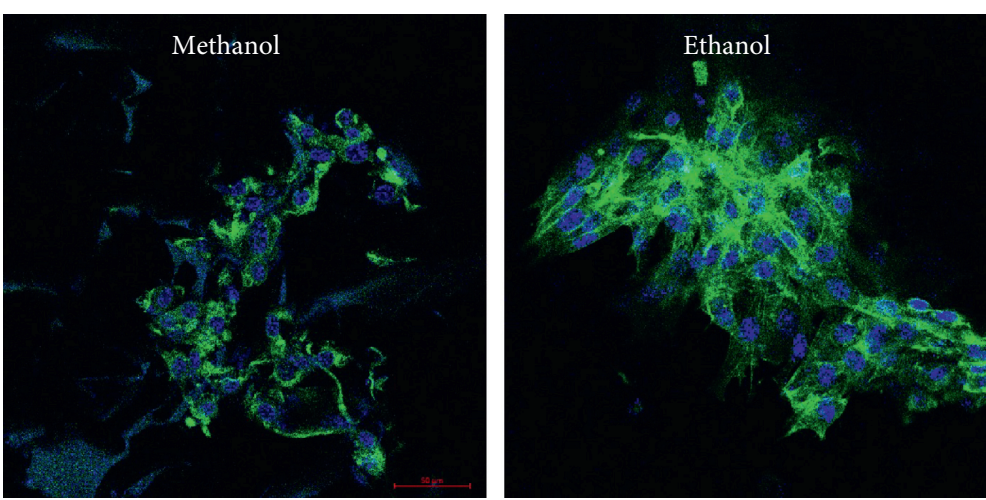

(a)

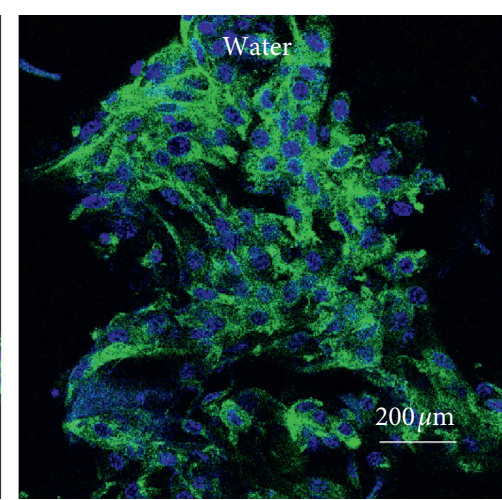

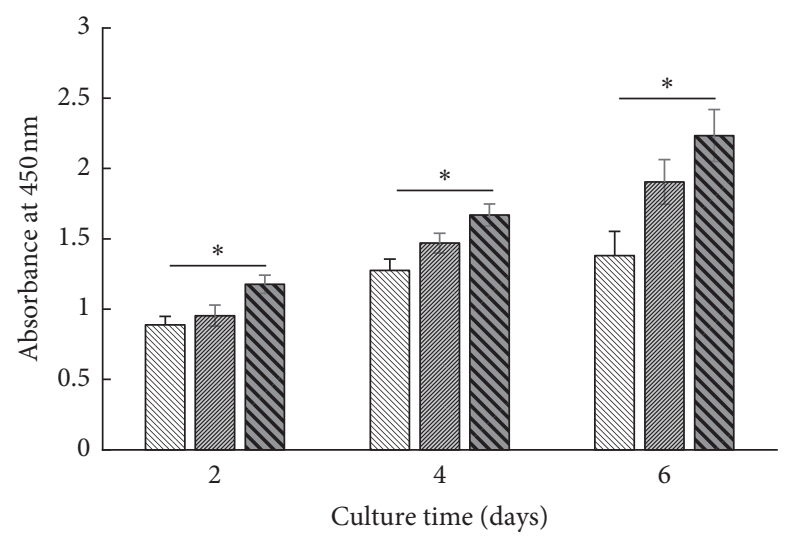

$\mathbb{B}$ Methanol-rinsed
Ethanol-rinsed
$\mathbf{\nabla}$ Water-rinsed

(b)

FiguRE 6: Confocal microscopy of BMSCs on silk scaffolds at day 4 (a) and CCK-8 assay of BMSCs proliferation on silk scaffolds ( $\left.{ }^{*} p<0.05\right)(\mathrm{b})$.

with methanol or ethanol [25]. Taken together, a new waterrinse process was developed to fabricate porous silk scaffolds using the salt-leaching method, and the resulting silk scaffold showed improved cell compatibility.

\section{Conclusions}

A new process was found to form porous silk scaffolds for tissue engineering. The process employed FA to dissolve silk and water to rinse porogen, which avoid the post-treatment with organic solvents. Furthermore, because the process was much simpler than HFIP-based process and the silk-FA solution was very stable, it would offer benefits for industrial production with good reproducibility. Additionally, considering the good pore structure, controllable mechanical properties, and improved cell compatibility, the porous silk scaffolds formed by this process would be promising biomaterial for tissue engineering.

\section{Data Availability}

The data presented in this study are available from the corresponding author upon request.

\section{Conflicts of Interest}

The authors declare that they have no conflicts of interest.

\section{Acknowledgments}

This work was supported by the Nature Science Foundation of Jiangsu Province (SBK2020041082), Health Talents Project of Suzhou (GSWS2019017), Health Project of Suzhou Health Commission (KJXW2018019), and Key Disease Project of Suzhou Health Commission (LCZX201908).

\section{References}

[1] W. Z. Sun, D. A. Gregory, M. A. Tomeh, and X. B. Zhao, "Silk fibroin as a functional biomaterial for tissue engineering," International Journal of Molecular Sciences, vol. 22, no. 3, 2021.

[2] S. U. D. Wani, S. P. Gautam, Z. L. Qadrie, and H. V. Gangadharappa, "Silk fibroin as a natural polymeric based bio-material for tissue engineering and drug delivery systems-A review," International Journal of Biological Macromolecules, vol. 163, pp. 2145-2161, 2020.

[3] Q. Zhang, S. Yan, and M. Li, "Silk fibroin based porous materials," Materials, vol. 2, no. 4, pp. 2276-2295, 2009. 
[4] J. H. Choi, D. K. Kim, J. E. Song, J. M. Oliveira, R. L. Reis, and G. Khang, "Silk fibroin-based scaffold for bone tissue engineering," Advances in Experimental Medicine \& Biology, vol. 1077, pp. 371-387, 2018.

[5] Z. S. Zhang, Z. Z. Ding, J. W. Huang et al., "Green process to prepare water-insoluble silk scaffolds with silk I structure," International Journal of Biological Macromolecules, vol. 117, pp. 144-151, 2018.

[6] B. B. Mandal, A. Grinberg, E. Seok Gil, B. Panilaitis, and D. L. Kaplan, "High-strength silk protein scaffolds for bone repair," Proceedings of the National Academy of Sciences, vol. 109, no. 20, pp. 7699-7704, 2012.

[7] U.-J. Kim, J. Park, H. Joo Kim, M. Wada, and D. L. Kaplan, "Three-dimensional aqueous-derived biomaterial scaffolds from silk fibroin," Biomaterials, vol. 26, no. 15, pp. 2775-2785, 2005.

[8] I. C. Um, H. Y. Kweon, K. G. Lee, and Y. H. Park, "The role of formic acid in solution stability and crystallization of silk protein polymer," International Journal of Biological Macromolecules, vol. 33, no. 4-5, pp. 203-213, 2003.

[9] H. Lee, S. J. Park, M.-e. Lee et al., "Fabrication of nanofibers using fibroin regenerated by recycling waste silk selvage," Polymer Bulletin, vol. 77, no. 7, pp. 3853-3862, 2020.

[10] A. Bucciarelli, R. K. Pal, D. Maniglio et al., "Fabrication of nanoscale patternable films of silk fibroin using benign solvents," Macromolecular Materials and Engineering, vol. 302, no. 7, 2017.

[11] X. Zhang, M. R. Reagan, and D. L. Kaplan, "Electrospun silk biomaterial scaffolds for regenerative medicine," Advanced Drug Delivery Reviews, vol. 61, no. 12, pp. 988-1006, 2009.

[12] F. Zhang, B. Zuo, Z. Fan et al., "Mechanisms and control of silk-based electrospinning," Biomacromolecules, vol. 13, no. 3, pp. 798-804, 2012.

[13] R. Nazarov, H.-J. Jin, and D. L. Kaplan, "Porous 3-D scaffolds from regenerated silk fibroin," Biomacromolecules, vol. 5, no. 3, pp. 718-726, 2004.

[14] M. Stoppato, H. Y. Stevens, E. Carletti, C. Migliaresi, A. Motta, and R. E. Guldberg, "Effects of silk fibroin fiber incorporation on mechanical properties, endothelial cell colonization and vascularization of PDLLA scaffolds," Biomaterials, vol. 34, no. 19, pp. 4573-4581, 2013.

[15] L. Dong, S.-J. Wang, X.-R. Zhao, Y.-F. Zhu, and J.-K. Yu, “3Dprinted poly( $\varepsilon$-caprolactone) scaffold integrated with cellladen chitosan hydrogels for bone tissue engineering," Scientific Reports, vol. 7, no. 1, Article ID 13412, 2017.

[16] X. Li, J. Ming, and X. Ning, "Wet-spun conductive silk fibroin-polyaniline filaments prepared from a formic acid-shell solution," Journal of Applied Polymer Science, vol. 136, no. 9, 2019.

[17] Y. Xue, F. Wang, M. Torculas, S. Lofland, and X. Hu, "Formic acid regenerated mori, tussah, eri, Thai, and muga silk materials: mechanism of self-assembly," ACS Biomaterials Science \& Engineering, vol. 5, no. 12, pp. 6361-6373, 2019.

[18] S.-W. Ha, A. E. Tonelli, and S. M. Hudson, "Structural studies ofBombyxmoriSilk fibroin during regeneration from solutions and wet fiber spinning," Biomacromolecules, vol. 6, no. 3 , pp. 1722-1731, 2005.

[19] Y. Zhang, W. Fan, Z. Ma et al., "The effects of pore architecture in silk fibroin scaffolds on the growth and differentiation of mesenchymal stem cells expressing BMP7," Acta Biomaterialia, vol. 6, no. 8, pp. 3021-3028, 2010.

[20] H.-J. Jin, J. Park, V. Karageorgiou et al., "Water-stable silk films with reduced $\beta$-sheet content," Advanced Functional Materials, vol. 15, no. 8, pp. 1241-1247, 2005.
[21] O. Chaudhuri, L. Gu, D. Klumpers et al., "Hydrogels with tunable stress relaxation regulate stem cell fate and activity," Nature Materials, vol. 15, no. 3, pp. 326-334, 2016.

[22] L. D. Harris, B.-S. Kim, and D. J. Mooney, "Open pore biodegradable matrices formed with gas foaming," Journal of Biomedical Materials Research, vol. 42, no. 3, pp. 396-402, 1998.

[23] K. H. Vining and D. J. Mooney, "Mechanical forces direct stem cell behaviour in development and regeneration," $\mathrm{Na}$ ture Reviews Molecular Cell Biology, vol. 18, no. 12, pp. 728742, 2017.

[24] Q. Lu, X. Wang, S. Lu, M. Li, D. L. Kaplan, and H. Zhu, "Nanofibrous architecture of silk fibroin scaffolds prepared with a mild self-assembly process," Biomaterials, vol. 32, no. 4, pp. 1059-1067, 2011.

[25] X. Hu, K. Shmelev, L. Sun et al., "Regulation of silk material structure by temperature-controlled water vapor annealing," Biomacromolecules, vol. 12, no. 5, pp. 1686-1696, 2011. 